\title{
A REVIEW OF SCHOOL ENTRY IMMUNISATION CERTIFICATES IN THE MANLY, WARRINGAH AND PITTWATER AREA, 1995
}

Ann Glanville and Bijou Blick

Manly Hospital and Community Health Services

Northern Sydney Area Health Service

T his article reports on a review of immunisation certificates (issued under the Public Health Act 1991) in schools in the Manly, Warringah and Pittwater local government areas. The aims of the review were to assess compliance with the immunisation provisions of the Act, examine schools' difficulties in complying with the Act, and suggest ways of overcoming these difficulties.

The 1992 amendment of the Public Health Act $1991^{1}$ requires that school principals obtain immunisation certificates for all children entering school from 1994 onwards. This requirement serves three main purposes:

To improve immunisation rates among school-aged children.

To ensure that the immunisation status of all children can be readily determined by health authorities in the event of an outbreak of a vaccine-preventable disease in a school. To provide surveillance data on the immunisation status of schoolchildren in NSW.

Reviews of immunisation certificates in $\mathrm{Auburn}^{2}$ and in the Central Coast Area Health Service ${ }^{3}$ in 1994 raised concerns about the numbers of certificates presented and, more important, the high proportion of certificates which were incorrectly completed and hence technically invalid.

\section{METHODS}

The study was carried out in the second school term of 1995 . Ten primary schools (six government and four nongovernment) in the Manly, Warringah and Pittwater local government areas were selected at random from 58 primary schools in the area. We examined immunisation records for all the 1995 kindergarten enrolments and the records of students who were in year 1 in 1995 (i.e. those who had been in kindergarten in 1994).

The records retained by the schools comprised a mixture of official immunisation certificates and a variety of other documents. All records available on the school premises were examined by two members of the Community Health Services' school health team. Data were collected using a standard data collection sheet which included a list of definitions to ensure uniformity.

The immunisation certificate comprises four panels (Figure 1, page 121). The first panel is for the child's personal details name, address, date of birth, and school. The second panel records details of complete immunisation. The third panel records the reason for incomplete immunisation. The fourth panel is a declaration by the issuer of the certificate.

The following definitions were used in this review.

Complete immunisation: Section A was correctly completed with all boxes ticked and the appropriate box in the issuer declaration also ticked.

Incomplete immunisation: Section B was correctly completed and the appropriate box in the issuer declaration ticked.

Invalid certificate: The certificate was incorrectly completed - (i) there was a failure to tick all boxes in Section A or Section B, and/or (ii) the appropriate box in the issuer declaration was not ticked, and/or (iii) the issuer's identification was incomplete.

Invalid certificates and any other documentation available on individual children's immunisation history (for example, copies of sections of the Personal Health Record) were also examined to gather any further information on children's likely immunisation status.

\section{RESULTS}

The principals of all 10 schools which had been selected agreed to participate in the study. The 10 schools represented a 1995 student population of 1,065 in kindergarten ( 520 children) and year 1 ( 545 children). For the majority of certificates the issuer was a general practitioner.

Of year 1 students, 62 per cent had provided an immunisation certificate. Only 60 per cent of these had been correctly filled in, i.e. 37 per cent of the year 1 students had provided a correctly filled certificate.

A higher proportion (77 per cent) of 1995 kindergarten children had provided immunisation certificates, of which 63 per cent had been correctly filled in. Thus 45 per cent of the kindergarten children had provided a correctly filled certificate.

In both years the major errors in the certificates were the incorrect use of Section A. This accounted for 84 per cent of invalid certificates provided by kindergarten children and 50 per cent of those provided by year 1 students.

If the provision of a correctly filled certificate is taken as an indicator, only 34 per cent of children enrolled in kindergarten in 1994 and 45 per cent of children enrolled in 1995 would be considered fully immunised.

However, if an assessment of immunisation status were based on an examination of all available records (including invalid certificates and other forms of documentation), 58 per cent and 71 per cent of children enrolling in kindergarten in 1994 and 1995 respectively were likely to have been fully immunised.

If children who provided no documentation on their immunisation status are excluded, the immunisation rates were 87 per cent and 90 per cent for 1994 and 1995 kindergarten enrolees respectively. This is consistent with existing records in the Area based on parent recall ${ }^{4}$.

\section{DISCUSSION}

A reliable assessment of immunisation status could be made for only the 60 or 63 per cent of children with certificates which were correctly filled out. Twenty per cent of kindergarten children and 34 per cent of year 1 children in 1995 had provided no documentation of immunisation. In the event of an outbreak of a vaccine-preventable disease, these children would be considered to be unimmunised. This could lead to the unnecessary exclusion of large numbers of children from school or to significant time delays, created by the need to identify those children truly at risk, with a resultant adverse impact on outbreak control.

The immunisation certificate was also designed to provide surveillance data. The large number of invalid certificates (from 37 per cent of kindergarten children and 40 per cent of year 1 children) must reduce the utility of data from certificates for surveillance purposes. The new National 


\section{TABLE 3}

RESULTS OF SCHOOL IMMUNISATION SURVEY

\begin{tabular}{|lccc|}
\hline & Year 1 & Kindergarten & Total \\
\hline Total number of students & 545 & 520 & 1,065 \\
Pupils with Immunisation certificates & $62 \%(338)$ & $77 \%(401)$ & $69 \%(739)$ \\
'Complete' (as \% of all certificates) & $55 \%(187)$ & $59 \%(236)$ & $57 \%(423)$ \\
$\quad$ 'Incomplete' (as \% of all certificates) & $4 \%(15)$ & $4 \%(16)$ & $3 \%(31)$ \\
$\quad$ Invalid' (as \% of all certificates) & $40 \%(136)$ & $37 \%(149)$ & $39 \%(285)$ \\
Other documentation & $4 \%(24)$ & $2.5 \%(13)$ & $3 \%(37)$ \\
No Immunisation documentation & $34 \%(183)$ & $20 \%(106)$ & $27 \%(289)$ \\
$\begin{array}{l}\text { Minimum \% all pupils fully immunised } \\
\text { ('Complete' certificates) }\end{array}$ & $34 \%(187)$ & $45 \%(236)$ & $40 \%(423)$ \\
$\begin{array}{l}\text { Maximum \% all pupils fully immunised } \\
\text { (Based on clinical judgment) }\end{array}$ & $58 \%(315)$ & $71 \%(371)$ & $64 \%(686)$ \\
\hline
\end{tabular}

Childhood Immunisation Register may provide a mechanism for improving surveillance, but the register will not generate comprehensive data on school-aged children for 6-7 years.

Our results suggest that attention should be given to:

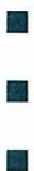
the design of the immunisation certificate, especially Section A; information for health professionals to promote correct filling in of the certificate; and

回 the dissemination of information to schools and the broader community.

With regard to the last point, there is a need to increase parental awareness of the requirement for immunisation certificates to be completed and presented for all children, regardless of their immunisation status at the time of school entry. School health services are well placed to do this in the course of their orientation talks to kindergarten parents and through their regular contact with schools.

\section{ACKNOWLEDGMENT}

We thank Susie Lough (CNS-Child and Family Health Service) for her participation in this project. We also acknowledge the support of the staff of the participating schools and Denise Wilton, clerical assistant at Queenscliff.

\section{END NOTE}

The study was repeated in 45 schools in the area in 1996, with the following results:

\begin{tabular}{l|c} 
& Kindergarten \\
\hline Total number of students & 2,285 \\
Pupils with immunisation certificates & $78 \%(1,775)$ \\
'Complete' (as \% of all certificates) & $54 \%(964)$ \\
'Incomplete' (as \% of all certificates) & $5 \%(82)$ \\
'Invalid' (as \% of all certificates) & $42 \%(739)$ \\
Other documentation & $4 \%(81)$ \\
No documentation & $19 \%(432)$
\end{tabular}

Although there was some increase in the proportion of students who presented certificates, a high proportion of these were still classified as 'invalid'.
1. New South Wales Immunisation Requirements for School Entry from 1994: Procedure Manual. NSW State Publication No (EB)92-87 1992.

2. Leckie R, Shah S, Jalaludin B. School Entry Immunisation Certificates: A Useful Tool for Immunisation Surveillance?

Communicable Diseases Intelligence 1996; 20:6-8.

3. Watt P. An evaluation of 1994 school entry immunisation certificates on the Central Coast of New South Wales. J Paediatr Child Health 1996; 32 (2): 125-131.

4. School Health Database, Manly Hospital and Community Health Services 1989-1993.

Despite extensive field testing of the immunisation certificate form design before its introduction, some problems with the use of the form have emerged. In 1997 the NSW Health Department plans to evaluate compliance with the immunisation provisions of the Public Health Act 1991. This will take into account three full years of experience with the provisions, which were introduced in 1994. Findings such as those reported here will feed into the evaluation. 